\title{
The Role of Family Obligations and School Adjustment in Explaining the Immigrant Paradox
}

\author{
Mitch van Geel $\cdot$ Paul Vedder
}

Received: 21 July 2009/Accepted: 12 October 2009/Published online: 27 October 2009

(C) The Author(s) 2009. This article is published with open access at Springerlink.com

\begin{abstract}
This study examined the role of family obligations and school adjustment in explaining immigrant adolescents' adaptation. Despite a relatively low socioeconomic status, immigrant adolescents have been found to have a pattern of adaptation superior to that of national adolescents. Immigrant adolescents' strong sense of family obligations and positive school adjustment have been used to explain these positive adaptation outcomes. Using selfreports in a sample of 277 national adolescents (45.5\% female) and a sample of 175 non-western immigrant adolescents (58.9\% female), both samples with a mean age of 15 years, it was found that despite a lower socio-economic status, the adaptation of immigrant adolescents was as good as the nationals' adaptation. Immigrant adolescents scored higher on family obligations and school adjustment. Family obligations and school adjustment were found positively related to adaptation outcomes in the national and the immigrant adolescent sample. Findings suggest that, in underprivileged environments, a strong sense of family obligations may help immigrants as well as national adolescents achieve a positive pattern of adaptation.
\end{abstract}

Keywords Family obligations · Immigrant adolescents · Adaptation

\section{Introduction}

Immigration is a complex and challenging process. Especially for immigrant adolescents, who do not yet have the full emotional and cognitive development that adults have,

M. van Geel $(\varangle) \cdot$ P. Vedder

Child Studies, Leiden University, Leiden, The Netherlands

e-mail: mgeel@fsw.leidenuniv.nl immigration and minority status may be very challenging. Constructing a positive ethnic identity, dealing with prejudice and discrimination and dealing with different expectations from the family and the new society may cause considerable stress (Berry et al. 1987; Gil et al. 1994; Hovey and King 1996). Furthermore, immigrant adolescents from non-western societies usually have to perform these tasks in underprivileged environments, as the socioeconomic status of these immigrants is consistently found to be lower than that of nationals (Hernandez and Darke 1999; Beiser et al. 2002; Zhou 1997a). It has been found that a low socio-economic status is related to lower intelligence, poorer socioemotional functioning, poorer health, increased substance use, and low scholarly achievement in children (Bradley and Corwyn 2002; McLoyd 1998). However, immigrant adolescents that have to deal with acculturative stress and a low socio-economic status do not necessarily have a poor pattern of adaptation.

Immigrant Paradox

It is not surprising that, in older literature, migration is presented as a risk factor to children's development (e.g., Aronowitz 1984). More recent insights and findings, however, suggest that migration does not necessarily lead to poor adaptation. Contrary to previous beliefs, immigrant adolescents are often found to perform as well as or even better than their national contemporaries on many forms of adaptation despite a lower socio-economic status. In a study conducted among 20,000 immigrant adolescents in the United States, first and second generation immigrant adolescents were less likely to engage in delinquent and violent acts, to use drugs or alcohol, and were less likely to be in poor health than national adolescents (Harris 2000). The pattern of lower substance use by immigrant adolescents 
than by national adolescents has been found in more studies (e.g., Blake et al. 2001; Brindis et al. 1995; Vega et al. 1993). Also, results have been reported that indicate that immigrant adolescents receive better grades in school than national adolescents (Fuligni 1997; Kao and Tienda 1995). The phenomenon that immigrant adolescents perform better in terms of adaptation than national adolescents despite lower socio-economic status has been labeled the immigrant paradox (Hayes-Bautista 2004; Garcia Coll 2005). This pattern has been found in the United States (Harker 2001) and Canada (Beiser et al. 2002). However, the support for an immigrant paradox in Europe is less clear-cut (Sam et al. 2008). It is likely that part of the secret to immigrants' remarkable adaptation can be explained by their strong sense of family obligations. Unlike western culture, in which individualism and self development is promoted, in many non-western cultures there is a strong reliance on and sense of obligation towards family members. In a study among Asian and South-American immigrant youth in the United States, it was indeed found that there is a far stronger sense of family obligations among immigrant adolescents than among national adolescents (Fuligni et al. 1999). Especially in explaining immigrant adolescents' positive school achievements this strong sense of family obligations has been found to be an important factor.

\section{Family Obligations and School Adjustment}

Especially for those immigrant adolescents in lower segments of society, a strong sense of family obligations may promote positive adaptation outcomes. It is in the lower segments of society that immigrant adolescents may be socialized into delinquent behavior and oppositional youth culture. Those adolescents with a strong sense of family obligations are more likely to obey their parents, resist the temptations of maladjustment and be motivated to do well in school (Portes and Zhou 1993; Zhou 1997a, b). Indeed, empirical findings generally indicate positive relationships between family obligations and adaptation outcomes (Fuligni 1997; Fuligni et al.1999). Immigrant adolescents see performing well in school as an important part of their family obligations, as they believe being successful in school will help them acquire good jobs in the future which will help them to take care of their families. However, the relationship between sense of family obligations and school adjustment is not linear: Those adolescents that reported the strongest sense of family obligations in the Fuligni et al. study (1999) did less well in school. It could be that because of their strong sense of family obligations they preferred to help their families immediately instead of spending time on school work. The same result was reported by Suarez-Orozco and Suarez-Orozco (1995) among Mexican immigrant adolescents. Nevertheless, a sense of family obligations is thought to be an important resource for most immigrant youth when it comes to their school adjustment.

\section{School Adjustment as Mediator}

A sense of family obligations may be important for adolescents' school adjustment; its role for other forms of adaptation is more circumstantial. Zhou and Bankston (1998) suggest that a strong sense of family obligations may keep adolescents from engaging in delinquency as they do not want to harm or embarrass their family. This implies a direct relationship between family obligations and behavioral problems. However, more factors may play a role in the positive adaptation of immigrant adolescents, and school adjustment has also been used to explain the positive pattern of adaptation reported by immigrant adolescents (Fuligni 1998; Steinberg 1996). School adjustment has been found positively related to adaptation (Bryant et al. 2003; Ludden and Eccles 2007; Vazsonyi and Pickering 2003). This could imply that school adjustment is a mediator between family obligations and different forms of adaptation. Adolescents who feel a strong sense of obligations towards their families will be better adjusted at school and through this increased school adjustment adolescents will experience a better adaptation in general. As of yet, school adjustment has not been studied as a mediator in the relationships between family obligations and adaptation. Studying this mediation would clarify whether family obligations have direct effects on adaptation or whether the positive effects of family obligations on adaptation can be partially or completely explained by an increased school adjustment.

\section{Junior Vocational Education; an Underprivileged} Setting for Adaptation

If indeed a strong sense of family obligations is an asset or resource for immigrant adolescents' adaptation in underprivileged environments, such effects should particularly be found for immigrant adolescents enrolled in junior vocational education. In many countries immigrants live under poorer socioeconomic conditions than the national population (Hernandez and Darke 1999; Zhou 1997b). Education should be the primary tool to help immigrants improve their poor socio-economic situation. Unfortunately, however, in the Netherlands there is an overrepresentation of immigrant adolescents in junior vocational education, which is the lowest educational track at secondary level in the Netherlands. In junior vocational education there is a relatively high drop out of students (Central Bureau of Statistics 2007; Scientific Advisory Board for Government Policy 2009). For the immigrant adolescents the situation is even more troublesome, not only are they overrepresented in junior vocational education, but compared to their national peers 
they also receive lower grades and drop out of junior vocational education more often (Central Bureau of Statistics 2008). Immigrant adolescents attending junior vocational education have relatively poor chances of improving their situation through education and thus may be seen as an example of a lower segment of society.

\section{The Current Study}

The goal of this study is to test whether there is an immigrant paradox among adolescents in junior vocational education. Furthermore, we will test whether family obligations and school adjustment can predict adaptation in an immigrant adolescent and a national adolescent sample. Earlier, Steinberg (1996) used school adjustment to explain positive adaptation outcomes, but did not include family obligations in his model. Fuligni used both family obligations and school adjustment to explain positive adaptation outcomes among immigrant adolescents, but only provided empirical evidence for the positive effects of family obligations on grades (Fuligni 1997, 1998; Fuligni et al. 1999). In this study the variables family obligations and school adjustment are used to predict a more comprehensive range of adaptation outcomes, namely school grades, self-esteem, psychological and behavioral problems. These analyses shall be conducted in a national and an immigrant adolescent sample.

The conclusion that an immigrant paradox exists is warranted if immigrant adolescents have a more positive pattern of adaptation than national adolescents, despite a lower socio-economic status. The first hypothesis is that the sample of immigrant adolescents in this study will have a lower socio-economic status than the national adolescents. In previous studies in the Netherlands it has already been reported that immigrant adolescents usually come from households with a lower socio-economic status than Dutch national adolescents (Central Bureau of Statistics 2008; Herweijer 2009). The second hypothesis is that immigrants perform better in terms of adaptation than nationals. We draw this hypothesis from immigrant paradox findings (e.g., Harker 2001). If the adaptation of immigrant adolescents in the Netherlands follows an immigrant paradox pattern these first two hypotheses should be supported.

The first two hypotheses focused on the possible existence of an immigrant paradox among immigrant adolescents in junior vocational education, whereas the third and fourth hypotheses will examine to what extent the adaptation of immigrant adolescents is related to a sense of family obligations and school adjustment. The third and fourth hypotheses are that immigrants score higher on family obligations and school adjustment than nationals (Fuligni 1997; Fuligni et al. 1999). Our final hypothesis is that in the immigrant adolescent sample school adjustment is a partial mediator in the relationships between family obligations and other aspects of adaptation. Partial mediation is expected as several scholars argue that family obligations have unique direct effects on adaptation and school adjustment (Fuligni 1998; Suarez-Orozco and Suarez-Orozco 1995; Zhou and Bankston 1998). The role of family obligations in national adolescents' adaptation has not received much attention in earlier studies (however, see Berry et al. 2006). In this study we will test the relationship between family obligations and adaptation in both a sample of immigrant adolescents and a sample of national adolescents. Given the scarcity of earlier studies no specific hypotheses are specified with respect to the national sample. By testing these hypotheses, we may gain insight in whether a strong sense of family obligations and a positive school adjustment contribute to the explanation of immigrant paradox findings.

As adaptation variables we choose self-esteem, psychological problems, behavioral problems and grade point average. These variables have been included in a study concerning the immigrant paradox in Europe (Sam et al. 2008) and a study concerning family obligations (Fuligni et al. 1999). The measures previously used by Sam et al. were found to be structurally equivalent across cultures, which is important when making cross-cultural comparisons. By using similar variables, this study may serve as a further validation of previous results.

\section{Method}

\section{Participants}

A total of 277 Dutch national students and 175 non western immigrant students completed the questionnaires. In addition, nineteen western immigrants participated in the data collection. Since the number of western immigrants was too small to be meaningfully included in the analyses they were removed from the dataset. The students were spread out across eight schools and 27 classrooms. The mean age of the national students was $14.52(\mathrm{SD}=.97)$, and the mean age of the immigrant students was $14.64(\mathrm{SD}=1.20)$. The national sample consisted of 150 boys and 126 girls, one respondent did not answer the question concerning gender. The immigrant sample consisted of 72 boys and 103 girls. Forty one had a Turkish cultural background (9.1\%), 39 a Moroccan (8.6\%), 16 a Surinamese (3.5\%), 16 an Antillean (3.5\%), and 63 immigrant adolescents (13.9\%) had a different cultural background. They originated from Afghanistan, Algeria, Argentina, the Dominican Republic, the Philippines, Sri- Lanka, Somalia, Senegal, Columbia, Lebanon, Russia, Taiwan, Vietnam, Egypt, Cap-Verde, Haiti and the People's Republic of China. 


\section{Instruments}

A survey consisting of several scales was administered to the students. The survey began with questions about demographics, namely age, gender, the birthplace of both parents of the respondent, the birthplace of the respondent and the respondents' religion.

\section{Socio-economic Status}

Socio-economic status was measured with the family affluence scale (Currie et al. 1997). A sample item of this scale is "How many computers does your family own". Since the scale has different response categories for the separate items Cronbach's alpha could not be computed. Higher scores are indicative of a higher socioeconomic status. The family affluence scale has been found to be a valid indicator of adolescents' socio-economic status (Boyce et al. 2006).

\section{Grade Point Average}

To get an indication of students' grade point average we asked students to report their last report grades for Dutch language, English language and math. The mean of these three grades was used in the analyses. The grade point average can vary between one through ten, in which one is the lowest and ten is the highest possible score.

\section{Family Obligations}

The scale used to measure family obligations was developed by Georgas et al. (1996). It consists of fourteen items which are answered on a five point scale ranging from "completely disagree" up to "completely agree". Sample items are "Children should obey their parents" and "A child has to take care of its parents when they need help". A higher total score indicates a stronger sense of family obligations. The Cronbachs' alphas were .73 for the immigrant sample and .66 for the national sample.

\section{School Adjustment}

The school adjustment questionnaire was adapted from the ICSEY-study (Berry et al. 2006). It consists of six items which are answered on a five point scale ranging from "completely disagree" up to "completely agree". Sample items are "I would like to quit school completely" and "I dislike going to school in the morning". Five items were reverse coded so that a higher total score is indicative of a better school adjustment. In the ICSEY study this scale was found to have a unifactorial factor structure and to be structurally equivalent across different ethnic groups. The
Cronbachs' alphas were .63 for the immigrant sample and .70 for the national sample.

\section{Self-esteem}

To measure self-esteem we used the Rosenberg's (1965) self-esteem inventory. It consists of ten items which are answered on a five point scale ranging from "completely disagree" up to "completely agree". A sample item is "On the whole I am satisfied with myself". A higher score indicated higher self-esteem. The Cronbachs' alphas were .83 for the immigrant sample and .89 for the national sample.

\section{Psychological Problems}

The psychological problems scale was taken from the ICSEY-study (Berry et al. 2006) and consisted of 15 items answered on a five-point scale ranging from "never" up to "very often". A sample item is "I feel restless". A higher score was indicative of more psychological problems. In the ICSEY study this scale was found to have a unifactorial factor structure and to be structurally equivalent across different ethnic groups. The Cronbachs' alphas were .92 for the immigrant sample and .90 for the national sample.

\section{Behavioral Problems}

The behavioral problems questionnaire was an adaptation of Olweus' antisocial behavior scale (Olweus 1989, 1994). The original scale has been shown to have a good construct validity and reliability (Bendixen and Olweus 1999). The Cronbachs' alphas were .85 for the immigrant sample and .80 for the national sample. The scale consisted of ten items. The items were scored on a five point scale ranging from "never" up to "more than 3 times during the past 12 months". A sample item of this questionnaire is: "had a serious fight with a teacher".

\section{Procedure}

Forty-eight junior vocational schools in the Netherlands with an ethnically diverse student body were invited to participate in a survey about multiculturalism and adaptation. Schools were first contacted via telephone. Only schools in the urbanized western part of the Netherlands were contacted, as these schools have ethnically diverse student populations. We followed a convenience sampling approach since there is no register available of schools and tracks and the ethnic composition of their student body. When schools showed an interest in the study, an appointment was made to explain the study in more detail. This led to seven schools participating in the study. Prior to 
the data collection, the teachers were informed about the goal of the study and letters of informed consent were sent to the students' parents. If parents did not want their children to participate in the study, they could contact the researcher. No parents made use of this possibility. Strict anonymity was promised for the schools, the teachers and the students. The questionnaires were administered in the classroom during school hours under the supervision of a teacher and a researcher. Students were informed that participation in the study was entirely voluntary. No students decided to withdraw from the study. All questionnaires were written in Dutch. The research assistants received no indication from the teachers or the students that the Dutch fluency of any of the immigrant students was insufficient to understand the questionnaire. This was not to be expected as following education in junior vocational education requires good command of the Dutch language. Prior to the admission of the questionnaires the teachers received instructions.

\section{Results}

To analyze whether nationals scored higher on the SES than immigrants, a $t$-test was computed. The $t$-test indicated that there was a significant difference between immigrants and nationals, with immigrants $(M=2.41, \mathrm{SD}=.46)$ scoring significantly lower than nationals $(M=2.69, \mathrm{SD}=.42)$, $t(453)=(6.487), p<.05$, with a medium effect size, Cohen's $D=.64$. This indicates that immigrant adolescents score substantially lower than nationals on the SES scale, although they were all in the same schools and classes.

To test for an immigrant paradox a MANOVA was computed. The immigrants were compared to the nationals on the variables grade point average, self-esteem, behavioral problems and psychological problems. As the number of boys and girls differed substantially for both the immigrant and the national adolescent samples, gender was added as a variable in the design. The means and standard deviations are reported in Table 1. The multivariate test indicated that there were no significant differences between the national and immigrant adolescent samples [Wilks' lambda $\left.F(3,438)=.1 .297, p>.05, \eta^{2}=.01\right]$. Subsequent ANOVAs indicated that immigrant adolescents did not experience more behavioral problems $[F(1,440)=.893$, $\left.p>.05, \eta^{2}=.00\right]$ or psychological problems $[F(1,440)=$ $\left.2.082, p>.05, \eta^{2}=.01\right]$, and did not differ in terms of self-esteem $\left[F(1,440)=1.512, p>.05, \eta^{2}=.00\right]$, when compared with the nationals. There was a multivariate effect for gender [Wilks' lambda $F(3,438)=.24 .944$, $\left.p<.05, \eta^{2}=.15\right]$. Subsequent ANOVAs indicated that girls experienced fewer behavioral problems $[F(1,440)=$ 12.689, $p<.05, \eta^{2}=.03$ ], more psychological problems
Table 1 Means and standard deviations (between brackets) for the variables school grades, self-esteem, psychological problems and behavioral problems

\begin{tabular}{|c|c|c|c|c|}
\hline & \multicolumn{2}{|l|}{ Immigrants } & \multicolumn{2}{|l|}{ Nationals } \\
\hline & Boys & Girls & Boys & Girls \\
\hline School grades & 7.08 (.97) & $6.91(.97)$ & $6.88(.84)$ & $6.81(.91)$ \\
\hline Self-esteem & $3.85(.71)$ & $3.79(.85)$ & $4.05(.76)$ & $3.43(.83)$ \\
\hline $\begin{array}{l}\text { Psychological } \\
\text { problems }\end{array}$ & 1.97 (.67) & $2.44(.79)$ & $2.05(.60)$ & $2.52(.66)$ \\
\hline Behavioral problems & $2.14(1.01)$ & $1.72(.70)$ & $1.90(.70)$ & $1.80(.73)$ \\
\hline
\end{tabular}

$\left[F(1,440)=48.625, p<.05, \eta^{2}=.01\right]$, and a lower selfesteem $\left[F(1,440)=21.055, p<.05, \eta^{2}=.05\right]$, than boys did. There was a multivariate interaction effect between gender and nationality on adaptation [Wilks' lambda $[F(3$, $\left.438)=6.254, p<.05, \eta^{2}=.04\right]$. Subsequent ANOVAs indicated that there were no interaction effects for behavioral problems $\left[F(1,440)=2.568, p>.05, \eta^{2}=.01\right]$ or psychological problems $[F(1,440)=.010, p>.05$, $\left.\eta^{2}=.00\right]$, but that there was a significant interaction term for self-esteem $\left[F(1,440)=12.351, p<.05, \eta^{2}=.03\right]$. Immigrant boys scored lower than national boys in terms of self-esteem whereas immigrant girls scored higher than national girls in terms of self-esteem.

As the immigrant adolescents scored lower on socioeconomic status than the nationals and socio-economic status may have effects on adaptation, we reran the MANOVA described above and added socio-economic status as a covariate. There was a significant multivariate effect for nationality [Wilks' lambda $F(4,394)=2.727, p<.05$, $\left.\eta^{2}=.03\right]$ and a significant multivariate interaction effect between gender and nationality [Wilks' lambda $F(4$, $\left.394)=2.727, p<.05, \eta^{2}=.03\right]$. A series of follow up ANCOVAs indicated that immigrants scored significantly higher grades than nationals $[F(1,397)=4.343, p<.05$, $\left.\eta^{2}=.01\right]$. A marginally significant effect indicated that immigrant adolescents experienced fewer behavioral problems than nationals $[F(1,397)=1.673, p<.10$, $\left.\eta^{2}=.01\right]$. An interaction effect indicated that immigrant adolescent girls had a higher self-esteem than national adolescent girls $\left[F(1,397)=7.129, p<.05, \eta^{2}=.03\right]$.

An ANOVA was computed to analyze whether immigrants scored higher on the family obligations scale than nationals. To account for the unbalanced number of boys and girls, gender was added in the design. The ANOVA yielded a significant difference between immigrants and nationals, with immigrants $(M=3.06, \mathrm{SD}=.60)$ embracing family obligations more strongly than nationals $(M=2.57$, $\mathrm{SD}=.50),\left[F(1,441)=96.737, p<.05, \eta^{2}=.18\right]$. This indicates that immigrant adolescents embrace family obligations much more strongly than western adolescents. The 
means and standard deviations are reported in Table 1 . There was no significant effect of gender $[F(1,441)=.870$, $\left.p>.05, \eta^{2}=.00\right]$, and there was no significant interaction effect $\left[F(1,441)=1.160, p>.05, \eta^{2}=.00\right]$.

To analyze whether immigrants scored higher on the school adjustment scale than nationals, an ANOVA was computed. To account for the unbalanced number of boys and girls, gender was added in the design. The ANOVA indicated that there was a significant difference between immigrants and nationals, with immigrants $(M=3.61$, $\mathrm{SD}=.80)$ scoring significantly higher than nationals $(M=3.35, \quad \mathrm{SD}=.84), \quad[F(1,446)=7.350, \quad p<.05$, $\left.\eta^{2}=.02\right]$. This indicates that immigrant adolescents had a better school adjustment than the national adolescents. The means and standard deviations are reported in Table 1. There was no significant effect of gender $[F(1,446)=.870$, $\left.p>.05, \eta^{2}=.00\right]$, and there was no significant interaction effect $\left[F(1,446)=1.160, p>.05, \eta^{2}=.00\right]$.

To test the relationships between family obligations, school adjustment and adaptation, we ran mediation analyses in the national and immigrant samples. To test for mediation, we used the stepwise method described by Baron and Kenny (1986). The correlations between the variables are reported in Table 2. Positive relationships between family obligations and school adjustment were found in both the national and the immigrant adolescent sample. In the immigrant sample partial mediation was found for the variables behavioral problems and self-esteem. These partial mediations indicated that family obligations and school adjustment both had unique contributions to a higher selfesteem and fewer behavioral problems. Furthermore it was found that family obligations were related to a higher grade point average, but this relationship was not mediated by school adjustment. The results of the regression analyses in the immigrant sample are summarized in Table 3.

In the national sample, partial mediation was found for the variable behavioral problems. This partial mediation indicated that family obligations and school adjustment both had unique contributions to fewer behavioral problems. A full mediation was found between family obligations, school adjustment and psychological problems. This means that the relationship between a stronger sense of family obligations and fewer psychological problems can be fully explained through school adjustment in the national sample. The results of the regression analyses in the national sample are summarized in Table 4.

Table 2 Pearson correlation coefficients for the variables in this study

\begin{tabular}{|c|c|c|c|c|c|c|}
\hline Nationals: & SES & Fam.o. & School & GPA & Ps.prob. & Beh.prob. \\
\hline \multicolumn{7}{|l|}{ Immigrant } \\
\hline SES & & -.004 & .042 & $.139 *$ & -.069 & $.132 *$ \\
\hline Family obligations & -.107 & & $.148^{*}$ & .036 & $-.140 *$ & $-.202 * *$ \\
\hline School adjustment & -.116 & $.208 * *$ & & $.253 * *$ & $-.372 * *$ & $-.453 * *$ \\
\hline GPA & .078 & $.200 *$ & .142 & & -.104 & $-.189^{*}$ \\
\hline Psychological problems & -.032 & -.026 & $-.378 * *$ & -.096 & & $.193 * *$ \\
\hline Behavioral problems & $.191 *$ & $-.291 * *$ & $-.374 * *$ & -.035 & .042 & \\
\hline Self-esteem & .053 & $.227 * *$ & $.230 * *$ & .141 & $-.375 * *$ & .045 \\
\hline
\end{tabular}

$* p<.05 ; * * p<.01$

Table 3 Results of the regression analyses for the immigrant adolescent sample

\begin{tabular}{|c|c|c|c|c|c|c|c|c|}
\hline & Independent variable & Dependent variable & $F(d f)$ & $B$ & $\mathrm{SE}$ & $\beta$ & $R^{2}$ & $\overline{R^{2} \text { change }}$ \\
\hline \multirow[t]{4}{*}{ Step 1} & Fam.obl. & GPA & $6.276(1,150)$ & .315 & .126 & $.200 *$ & $.04 *$ & \\
\hline & Fam.obl. & Psych. & $.111(1,168)$ & -.033 & .099 & -.026 & .00 & \\
\hline & Fam.obl. & Beh. prob. & $15.346(1,166)$ & -.407 & .104 & $-.291 * *$ & $.09 * *$ & \\
\hline & Fam.obl. & Self-est & $9.201(1,170)$ & .294 & .097 & .227 & $.05 * *$ & \\
\hline Step 2 & Fam.obl. & School adj & $7.708(1,170)$ & .278 & .100 & $.208 * *$ & $.04 * *$ & \\
\hline \multirow[t]{6}{*}{ Step 3} & Fam.obl. & GPA & $3.968(2,149)$ & .278 & .129 & $.177^{*}$ & $.05^{*}$ & .04 \\
\hline & School adj & & & .123 & .096 & .105 & & .01 \\
\hline & Fam.obl. & Beh. prob. & $19.100(2,165)$ & -.319 & .100 & $-.227 * *$ & $.19 * *$ & .09 \\
\hline & School adj & & & -.346 & .075 & $-.328 * *$ & & .10 \\
\hline & Fam.obl. & Self-est & $7.567(2,169)$ & .246 & .098 & $.189 *$ & $.08 * *$ & .05 \\
\hline & School adj & & & .175 & .073 & $.180 *$ & & .03 \\
\hline
\end{tabular}

$* p<.05 ; * * p<.01$ 
Table 4 Results of the regression analyses for the national adolescent sample

\begin{tabular}{|c|c|c|c|c|c|c|c|c|}
\hline & Independent variable & Dependent variable & $F(d f)$ & $B$ & SE & $\beta$ & $R^{2}$ & $\overline{R^{2} \text { change }}$ \\
\hline \multirow[t]{4}{*}{ Step 1} & Fam. & GPA & $.323(1,251)$ & .064 & .112 & .036 & .00 & \\
\hline & Fam. & Psych. & $5.425(1,272)$ & -.187 & .080 & $-.140 *$ & $.02 *$ & \\
\hline & Fam. & Beh. prob. & $11.559(1,272)$ & -.300 & .088 & $-.202 * *$ & $.04 * *$ & \\
\hline & Fam. & Self & $.008(1,272)$ & .009 & .104 & .005 & .00 & \\
\hline Step 2 & Fam. & School & $6.113(1,272)$ & .254 & .103 & $.148^{*}$ & $.02 *$ & \\
\hline \multirow[t]{4}{*}{ Step 3} & Fam. & Psych & $23.279(2,271)$ & -.115 & .076 & -.086 & $.15^{* *}$ & .02 \\
\hline & School & & & -.281 & .044 & $-.360 * *$ & & .14 \\
\hline & Fam. & Beh. prob. & $39.067(2,271)$ & -.205 & .080 & $-.138 *$ & $.22 * *$ & .04 \\
\hline & School & & & -.375 & .047 & $-.433^{* *}$ & & .18 \\
\hline
\end{tabular}

$* p<.05 ; * * p<.01$

\section{Discussion}

The aim of this study was to test for an immigrant paradox among immigrant adolescents in the Netherlands and to analyze the relationships between family obligations, school adjustment and adaptation in an immigrant and national adolescent sample. Based on immigrant paradox findings (e.g., Hayes-Bautista 2004; Garcia Coll 2005) the immigrant adolescents were expected to score better on measures of adaptation than national adolescents. However, the results provided no clear support for an immigrant paradox. When we reran the analysis with socio-economic status as a covariate, it was found that immigrant adolescents had higher grades and there was a marginally significant effect for behavioral problems. Immigrant girls had a significantly higher self-esteem than national adolescent girls. This pattern of adaptation is not as spectacular as the immigrant paradox findings in American and Canadian studies (Beiser et al. 2002; Harker 2001), but it is similar to previous European results (Sam et al. 2008). A particular aspect of the immigrant paradox is that immigrants tend to lose their benefit in terms of adaptation when they become more assimilated in the national society (Sam et al. 2008), eventually resulting in an adaptation pattern that is the opposite of an immigrant paradox. This phenomenon is well documented in the US (Jasso et al. 2004; Rumbaut 1999; Suarez-Orozco and Suarez-Orozco 2002), but may not materialize in the Netherlands. In the Netherlands, there is a more extensive and accessible social welfare system than in the United States (Alesina et al. 2001; Gustafsson and Stafford 1994). The accessibility of health care and welfare in the Netherlands may ensure that all ethnic groups and social classes are doing relatively well, and as such not allow for large differences in levels of adaptation.

More importantly, the immigrant adolescents in this study did not score worse in terms of adaptation than their national contemporaries, despite a strong disadvantage in terms of socio-economic status. As there are many developmental risks associated with poor socio-economic conditions (Bradley and Corwyn 2002; McLoyd 1998), it is remarkable that immigrant adolescents show as good an adaptation as national adolescents. Immigrant adolescents had a stronger sense of family obligations and a better school adjustment than national adolescents. This is in line with previous studies (Fuligni 1997; Fuligni et al. 1999; Steinberg 1996). In this study, a sample of non-western immigrant adolescents was used. They are more likely than national adolescents to embrace collectivistic values. As such, they may place a higher importance on helping, obeying and spending time with family members. Because immigrant adolescents see the sacrifices their families made to come to the new country for their better futures, and because they see school as a possibility to help their families in the future, they are usually well motivated to perform well in school (Fuligni 1998; Zhou and Bankston 1998).

For the immigrant adolescent sample, we hypothesized that the relationships between family obligations and mean grades, behavioral problems, psychological problems and self-esteem were partially mediated by school adjustment. We formulated this hypothesis based on literature that states that a strong sense of family obligations is related to a better school adjustment and a more positive pattern of adaptation (Fuligni 1997; Fuligni et al. 1999. Zhou and Bankston 1998), and to literature that states that school adjustment is related to a better pattern of adaptation (Bryant et al. 2003; Ludden and Eccles 2007; Steinberg 1996; Vazsonyi and Pickering 2003). The correlations indicated that in the immigrant adolescent sample family obligations were related to better grades, a better school adjustment, higher self-esteem, and fewer behavioral problems. The relationships between family obligations and self-esteem and family obligations and behavioral problems were partially mediated by school adjustment. These partial mediation effects indicate that part of the effect of family obligations on self-esteem and behavioral problems can be explained through school adjustment, but there is also a direct effect of 
family obligations on behavioral problems and self-esteem. Thus, the hypotheses were confirmed for two of the four measures of adaptation. In the national adolescent sample the correlations table indicated that a stronger sense of family obligations was related to a better school adjustment, fewer psychological problems and fewer behavioral problems. The relationship between family obligations and psychological problems was fully mediated by school adjustment and the relationship between family obligations and behavioral problems was partially mediated by school adjustment. The full mediation between family obligations and psychological problems indicates that the effect of family obligations on psychological problems can be completely explained by the better school adjustment.

In the national adolescent sample, the positive relationships that were found between family obligations and school adjustment and behavioral problems may be explained by the same process as in the immigrant adolescent sample. Those adolescents, national or immigrant, who feel a strong sense of obligation to their families may take more of an effort to do well in school to make their families proud and may be more hesitant to engage in delinquent acts to avoid bringing shame to their families. But what explains the differences between these two groups, why are family obligations related to self-esteem and mean grades in the immigrant but not in the national sample? Even more than national adolescents, immigrant adolescents may feel that they have a debt to pay to their parents who migrated so that they could have a better future. As such, approval of family members may be even more important, and those adolescents who are obedient to their parents may feel a sense of fulfillment translating in better self-esteem whereas those immigrant adolescents that disobey parents may feel more ashamed, which may translate into a lower self-esteem. The lower socio-economic status that immigrant adolescents likely grew up in may explain the relationship between family obligations and grades. Immigrant adolescents may feel a stronger need to help their families overcome comparatively poor living standards, and getting good grades may qualify them for a better education and a better job later (Freeburg and Stein 1996).

\section{Limitations and Prospects}

This study has several limitations. The reliabilities of the family obligations and school adaptation scales are on the low side. By using the variables self-esteem, behavioral problems, psychological problems and grades as dependent variables in the design, we aimed to provide a better understanding of the immigrant paradox. Given the inconclusive pattern of results in this study-full mediation, partial mediation and no mediation were found, other models need to be considered in future studies. Self-esteem was used as a dependent variable but it can be argued that self-esteem causes a better school adjustment (Rosenberg et al. 1995), while a reciprocal relationship between selfesteem and school achievement has also been suggested (Rosenberg et al. 1989). School adjustment has in this study been used as a predictor for behavioral and psychological problems, but it may be that behavioral and psychological problems lower a students' motivation to do well in school. While this study provides evidence that family obligations and school adjustment are related to better adaptation outcomes in immigrant and national adolescents, the specific relationship between the variables remains unclear. New studies with longitudinal designs are needed to clear this up. Nonetheless, the results from this study that immigrant adolescents score higher on school adjustment and family obligations than national adolescents, and that family obligations and school adjustment are related to a higher self-esteem and fewer behavioral problems, suggest that family obligations and school adjustment may indeed be important factors in explaining the immigrant paradox.

An interesting finding is that national adolescents also seem to benefit from a strong sense of family obligations. However, they score substantially lower on family obligations than immigrant adolescents. This may provide an interesting opportunity for nationals, as learning from the immigrant community to increase the sense of family obligations may help improve national adolescents' adaptation. Acculturation is a two way street as prolonged contact between cultural groups can change the culture of both groups. Ideally, this would entail positive changes for both groups. However, in the Netherlands there is a growing demand for immigrant groups to forsake their ethnic cultures and completely assimilate in mainstream Dutch culture (Arends-Toth and Van de Vijver 2003; Van Oudenhoven et al. 1998). This is unfortunate as forcing immigrants to completely abandon their ethnic culture does not only deprive immigrants from the means to ensure a positive adaptation but also robs nationals from valuable acculturation opportunities.

Open Access This article is distributed under the terms of the Creative Commons Attribution Noncommercial License which permits any noncommercial use, distribution, and reproduction in any medium, provided the original author(s) and source are credited.

\section{References}

Alesina, A., Glaeser, E., \& Sacerdote, B. (2001). Why doesn't the US have a European-style welfare state? Brookings Papers on Economic Activity, 2, 187-277.

Aronowitz, M. (1984). The social and emotional adjustment of immigrant children: A review of the literature. International Migration Review, 18, 237-257.

Arends-Toth, J. V., \& Van de Vijver, F. J. R. (2003). Multiculturalism and acculturation: Views of Dutch and Turkish-Dutch. European Journal of Social Psychology, 33, 249-266. 
Baron, R. M., \& Kenny, D. A. (1986). The moderator-mediator distinction in social psychological research: Conceptual, strategic and statistical considerations. Journal of Personality and Social Psychology, 51, 1173-1182.

Beiser, M., Hou, F., Hyman, I., \& Tousignant, M. (2002). Poverty, family process, and the mental health of immigrant children in Canada. American Journal of Public Health, 92, 220-227.

Bendixen, M., \& Olweus, D. (1999). Measurement of antisocial behaviour in early adolescence and adolescence: Psychometric properties and substantive findings. Criminal Behaviour and Mental Health, 9, 323-354.

Berry, J. W., Kim, U., Minde, T., \& Mok, D. (1987). Comparative studies of acculturative stress. International Migration Review, $21,491-511$

Berry, J. W., Phinney, J. S., Sam, D., \& Vedder, P. (Eds.). (2006). Immigrant youth in cultural transition: Acculturation, identity and adaptation across national contexts. Mahwah: Lawrence Erlbaum Assosiates.

Blake, S. M., Ledsky, R., Goodenow, C., \& O’Donnell, L. (2001). Recency of immigration, substance use, and sexual behavior among Massachusetts adolescents. American Journal of Public Health, 91, 794-798.

Boyce, W., Torsheim, T., Currie, C., \& Zambon, A. (2006). The family affluence scale as a measure of national wealth: Validation of an adolescent self-report measure. Social Indicators Research, 78, 473-487.

Bradley, R. H., \& Corwyn, R. F. (2002). Socioeconomic status and child development. Annual Review of Psychology, 53, 371-399.

Brindis, C., Wolfe, A. L., McCaiter, V., Ball, S., \& Starbuck-Morales, S. (1995). The associations between immigrant status and riskbehavior patterns in Latino adolescents. Journal of Adolescent Health, 17, 99-105.

Bryant, A. L., Schulenberg, J. E., O’Malley, P. M., Bachman, J. G., \& Johnston, L. D. (2003). How academic achievement, attitudes, and behaviors relate to the course of substance use during adolescence: A 6-year, multiwave national longitudinal study. Journal of Research on Adolescence, 13, 361-397.

Central Bureau of Statistic. (2008). Jaarrapport integratie 2008 [Year report integration 2008]. The Netherlands: The Hague: SDU.

Central Bureau of Statistics. (2007). Jaarrapport onderwijs 2007 [Year report education 2007]. The Netherlands: The Hague: SDU.

Currie, C. E., Elton, R. A., Todd, J., \& Platt, S. (1997). Indicators of socio-economic status for adolescents: The WHO health behaviour in school-aged survey. Health Education Research, 12, $385-397$.

Freeburg, A., \& Stein, C. (1996). Felt obligation toward parents in Mexican-American and Anglo-American young adults. Journal of Social and Personal Relationship, 13, 457-471.

Fuligni, A. J. (1997). The academic achievement of adolescents from immigrant families: The roles of family background, attitudes, and behavior. Child Development, 68, 261-273.

Fuligni, A. J. (1998). The adjustment of children from immigrant families. Current Directions in Psychological Science, 7, 99-103.

Fuligni, A. J., Tseng, V., \& Lam, M. (1999). Attitudes toward family obligations among American adolescents with Asian, Latin American, and European backgrounds. Child Development, 70, $1030-1044$.

Garcia Coll, C. (2005). The immigrant paradox: Critical factors in Cambodian students' success. Paper presented at the 2005 Biennial meeting of the Society for Research in Child Development. Atlanta, GA, April 7-10.

Georgas, J., Berry, J., Shaw, A., Christakopoulou, S., \& Milonas, K. (1996). Acculturation of Greek family values. Journal of CrossCultural Psychology, 27, 329-338.
Gil, A., Vega, W., \& Dimas, J. (1994). Acculturative stress and personal adjustment among Hispanic adolescent boys. Journal of Community Psychology, 22, 43-54.

Gustafsson, S., \& Stafford, F. (1994). Three regimes of child-care: The United States, the Netherlands, and Sweden. In R. Blank (Ed.), Social protection versus economic flexibility (pp. 333362). Chicago: University of Chicago Press.

Harker, K. (2001). Immigrant generation, assimilation and adolescent psychological well-being. Social Forces, 79, 969-1004.

Harris, K. M. (2000). The health status and risk behaviors of adolescents in immigrant families. In D. Hernandez (Ed.), Children of immigrants: Health, adjustment, and public assistance (pp. 286-347). Washington, DC: National Academy Press.

Hayes-Bautista, D. (2004). La Nueva California: Latinos in the golden state. Los Angeles: University of California Press.

Hernandez, D. J., \& Darke, K. (1999). Socioeconomic and demographic risk factors and resources among children in immigrant and native-born families: 1910, 1960, and 1990. In D. J. Hernandez (Ed.), Children of immigrants: Health, adjustment, and public assistance (pp. 19-125). Washington, DC: National Academy Press.

Herweijer, L. (2009). Making up the gap: migrant education in the Netherlands. SCP: The Netherlands: The Hague.

Hovey, J. D., \& King, C. A. (1996). Acculturative stress, depression, and suicidal ideation among immigrant and second-generation Latino adolescents. Journal of the American Academy of Child and Adolescent Psychiatry, 35, 1183-1192.

Jasso, G., Massey, D. S., Rosenzweig, M. E., \& Smith, J. P. (2004). Immigrant health: Selectivity and acculturation. In N. B. Anderson, R. A. Bulatao, \& B. Cohen (Eds.), Critical perspectives on racial and ethnic differences in health in late life (pp. 227-266). Washington, DC: The National Academy Press.

Kao, G., \& Tienda, M. (1995). Optimism and achievement: The educational performance of immigrant youth. Social Science Quarterly, 76, 3-19.

Ludden, A. B., \& Eccles, J. S. (2007). Psychosocial, motivational, and contextual profiles of youth reporting different patterns of substance use during adolescence. Journal of Research on Adolescence, 17, 51-88.

McLoyd, V. C. (1998). Socioeconomic disadvantage and child development. American Psychologist, 53, 185-204.

Olweus, D. (1989). Prevalence and incidence in the study of antisocial behaviour: Definition and measurement. In M. Klein (Ed.), Cross-national research in self-reported crime and delinquency (pp. 187-201). Dordrecht: Kluwer Academic.

Olweus, D. (1994). The revised Olweus Bully/Victim Questionnaire. Bergen: Research Center for Health Promotion, University of Bergen.

Portes, A., \& Zhou, M. (1993). The new second generation: Segmented assimilation and its variants. Annals of the American Academy of Political \& Social Science, 530, 74-96.

Rosenberg, M. (1965). Society and the adolescent self-image. Princeton: Princeton University Press.

Rosenberg, M., Schooler, C., \& Schoenbach, C. (1989). Self-esteem and adolescent problems: Modeling reciprocal effects. American Sociological Review, 54, 1004-1018.

Rosenberg, M., Schooler, C., Shoenbach, C., \& Rosenberg, F. (1995). Global self-esteem and specific self-esteem: Different concepts, different outcomes. American Sociological Review, 60, 141156.

Rumbaut, R. G. (1999). Assimilation and its discontents: Ironies and paradoxes. In C. Hirschman, P. Kasinitz, \& J. DeWind (Eds.), The handbook of international migration: The American Experience (pp. 172-195). New York: Russel Sage foundation.

Sam, D. L., Vedder, P., Liebkiend, K., Neto, F., \& Virta, E. (2008). Immigration, acculturation and the paradox of adaptation in 
Europe. European Journal of Developmental Psychology, 5, $138-158$

Scientific Advisory Board for Government Policy. (2009). Vertrouwen in de school [Trusting the school]. Amsterdam: Amsterdam University Press.

Steinberg, L. (1996). Beyond the classroom: Why school reform has failed and what parents need to do. New York: Simon \& Schuster.

Suarez-Orozco, C., \& Suarez-Orozco, M. M. (1995). Transformations: Immigration, family life, and achievement motivation among Latino adolescents. Stanford: Stanford University Press.

Suarez-Orozco, C., \& Suarez-Orozco, M. M. (2002). Children of immigrants. Cambridge: Harvard University Press.

Van Oudenhoven, J. P., Prins, K. S., \& Buunk, B. P. (1998). Attitudes of minority and majority members towards adaptation of immigrants. European Journal of Social Psychology, 28, 9951013.

Vazsonyi, A. T., \& Pickering, L. E. (2003). The importance of family and school domains in adolescent deviance: African American and Caucasian youth. Journal of Youth and Adolescence, 32, $115-128$.

Vega, W. A., Gil, A. G., \& Zimmerman, R. S. (1993). Patterns of drug use among Cuban-American, African-American, and White nonHispanic boys. American Journal of Public Health, 83, 257-259.

Zhou, M. (1997a). Segmented assimilation: Issues, controversies, and recent research on the new second generation. International Migration Review, 31, 923-960.
Zhou, M. (1997b). Growing up American: The challenge confronting immigrant children and children of immigrants. Annual Review of Sociology, 23, 63-95.

Zhou, M., \& Bankston, C. L. (1998). Growing up American: How Vietnamese children adapt to life in the United States. New York: Russel Sage Foundations.

\section{Author Biographies}

Mitch van Geel is a PhD. Student in the Department of Education and Child Studies at Leiden University, the Netherlands. He specializes in immigrant adolescents. His main interest is in the adaptation and acculturation of immigrant adolescents.

Paul Vedder is a professor of Clinical Child and Adolescent Studies, Department of Education and Child Studies at Leiden University, the Netherlands. He is a developmental psychologist with a primary interest in inter- (parent-child) and intragenerational (peer relationships) transmission processes and in the link between acculturation processes and adaptation outcomes in the domains of social competence, language proficiency, and the quality of interethnic relationships. 